\title{
Effects of weight change and physical activity on knee pain and health-related quality of life in East Asian women aged 50 years and older with knee osteoarthritis: a population-based study
}

\section{Young Choi ( $\nabla$ yuzo0n@naver.com )}

Kosin medical university https://orcid.org/0000-0001-8710-4168

Chongbum Chang

Seoul National University Seoul Metropolitan Government Boramae Medical Center

\section{Seung-Baik Kang}

Seoul National University Seoul Metropolitan Government Boramae Medical Center

Chin Youb Chung

Seoul National University Bundang Hospital

Moon Seok Park

Seoul National University Bundang Hospital

Kyoung Min Lee

Research article

Keywords: knee pain, health-related quality of life, weight change, physical activity, osteoarthritis

Posted Date: July 3rd, 2019

DOI: https://doi.org/10.21203/rs.2.11017/v1

License: (c) (i) This work is licensed under a Creative Commons Attribution 4.0 International License. Read Full License 


\section{Abstract}

Objective This study aimed to investigate the effects of weight change and physical activity on the level of knee pain and health-related quality of life in East Asian women with knee osteoarthritis using population-based data. Methods A total of 564 women (mean age, 68.2 years, standard deviation, 8.9 years) aged 50 years or older with knee osteoarthritis (Kellgren-Lawrence grade $\geq 2$ ) were included in the data analyses from the fifth Korea National Health and Nutrition Examination Survey. Data regarding the radiographic grade, weight change during the past year, physical activity, level of knee pain, and healthrelated quality of life (EuroQOL five-dimension [EQ-5D] index) were collected. Multiple regression analysis was performed to identify factors significantly affecting the level of knee pain and health-related quality of life in subgroups according to the body mass index (BMI) range $(\leq 22.5$, between 22.6 and 27.5 , and $>27.5 \mathrm{~kg} / \mathrm{m} 2$ ). Results In women with $22.5 \mathrm{~kg} / \mathrm{m} 227.5 \mathrm{~kg} / \mathrm{m} 2$, weekly hours of moderate-intensity activity showed significant negative correlation with EQ-5D. Conclusions The effects of weight change and physical activity on knee pain and health-related quality of life could be different according to BMI ranges. Well-designed interventions to improve both knee pain and health-related quality of life need to be investigated in future studies that would assess physical activity, diet, and weight changes.

\section{Introduction}

Knee osteoarthritis is one of the most prevalent orthopedic disorders that adversely affects the patients' health-related quality of life, especially in the elderly population(2-5)[1-4]. Knee pain is an important clinical parameter when determining the necessity of surgical treatment and the treatment outcomes[510]. Therefore, orthopedic surgeons need to understand the factors affecting the level of knee pain and quality of life in patients with knee osteoarthritis.

Previous studies showed that various factors could affect arthritic knee pain, including the radiographic grade of osteoarthritis, presence of spine or hip diseases, obesity, and even psychiatric disorders[11-17]. Obesity is known to affect arthritic pain by increasing mechanical load on the joint as well as by increasing inflammatory cytokine through the arachidonic pathway, which eventually could lead to development and progression of knee osteoarthritis[18-20]. Therefore, obesity has been acknowledged as an important modifiable factor that affects the prognosis of knee osteoarthritis[18, 21-26].

A study reported that weight loss and moderate activity were effective in improving function and pain in obese patients with knee osteoarthritis[18, 24, 26-28]. However, there is little evidence that weight loss is an effective treatment in nonobese patients, especially in the Asian population. Theoretically, body weight and physical activity could have complicated effects on the mechanical load on the joint, and their relationship could be a confounding factor when analyzing this effect.

This study aimed to investigate the effects of weight change and physical activity on knee pain and health-related quality of life in women with knee osteoarthritis (Kellgren-Lawrence grade $\geq 2$ ) using population-based data. 


\section{Materials And Methods \\ Subjects}

The Korean National Health and Nutrition Examination Survey (KNHNES) is a national population-based study conducted by the Korean Centers for Disease Control and Prevention annually from 1998 . The subjects are noninstitutionalized civilians who were randomly selected through stratified, multistage probability samples, which were based on age, sex, and residence area. This study includes questionnaires regarding health behavior and nutrition intake and health examinations such as body weight, height, blood pressure measurements, and blood tests. Specific health examinations are included according to the demand of national healthcare policies. Knee osteoarthritis examination and survey were performed in 2011.

A total of 10,589 population-based subjects were invited to participate in the 2011 survey, and 8518 agreed to participate, with a response rate of $80.4 \%$. Of these, 1956 women aged 50 years and older were included. Knee osteoarthritis was defined radiographically as Kellgren-Lawrence grade $\geq 2[7,29,30]$, which was evaluated by two skeletal radiologists. A total of 830 women with knee osteoarthritis were selected, and exclusion criteria were use of osteoarthritis medication, presence of malignancies, and incomplete dataset. Finally, 564 women with knee osteoarthritis were analyzed after implementing the inclusion and exclusion criteria (Figure 1).

Written informed consent was obtained by the Korean Centers for Disease Control and Prevention from all participants. Approval from the ethical committee was exempted by the institutional review board at our hospital because this study utilized a publicly available database and did not have any potential violation of patient rights.

\section{Data collection from the fifth KNHNES database}

Demographic data including age, sex, body mass index (BMI), weight change in the past year (gain $>10$ $\mathrm{kg}$, gain of $6-10 \mathrm{~kg}$, gain of $3-6 \mathrm{~kg}$, gain $<3 \mathrm{~kg}$, no change, loss $<3 \mathrm{~kg}$, loss of $3-6 \mathrm{~kg}$, loss of $6-10 \mathrm{~kg}$, and loss $>10 \mathrm{~kg}$ ) was collected. The parameters of height and weight were measured using standardized instruments, and BMI was calculated using the height and weight measurements. The percentage of weight change was calculated by dividing the weight change with body weight. Presence of malignant diseases and use of osteoarthritis medication were recorded using a health information questionnaire. The short form of the International Physical Activity Questionnaire[31] was used to evaluate the subjects' activity level, and weekly hours of vigorous-intensity, moderate-intensity, and walking activities were recorded.

Health-related quality of life was measured using the EuroQOL five-dimension (EQ-5D) index. The system comprises five dimensions including mobility, self-care, usual activities, pain/discomfort, and anxiety/depression[32, 33]. 
The knee osteoarthritis survey included severity of knee pain and radiographic examination. The severity of knee pain was evaluated using a 10-point numerical rating scale (NRS) ( $0=$ no pain, $10=$ severe pain). Knee X-rays were taken bilaterally with the subjects' weight-bearing using an SD 3000 Synchro Stand (Accele Ray, SYFM Co., Seoul, South Korea), and the radiographic images were digitally stored. Severity of radiographic knee osteoarthritis was evaluated using the Kellgren-Lawrence grading system[7, 29, 30] (grade 0 , no features of osteoarthritis; grade 1, small osteophytes of uncertain significance; grade 2, definite osteophytes without impairment of joint space; grade 3, definite osteophytes with moderate joint space reduction; grade 4, definite osteophytes with substantial joint space narrowing and subchondral bone sclerosis). Presence of knee osteoarthritis was defined as Kellgren-Lawrence grades 2, 3, and 4[7, $29,30]$. Radiographic evaluation was performed by two radiologists, and the agreement between the two was $85.2 \%$ for 81 randomly selected radiographic images with an intraclass correlation coefficient of 0.767 ( $95 \%$ confidence interval, 0.659 to 0.844 ). If a disagreement in radiographic findings between the two radiologists occurred, the higher grade was adopted.

\section{Data analysis and statistics}

Women with knee osteoarthritis were categorized into three groups according to BMI measurements: those with $\mathrm{BMI} \leq 22.5 \mathrm{~kg} / \mathrm{m}^{2}$, those with $22.5 \mathrm{~kg} / \mathrm{m}^{2}<\mathrm{BMI} \leq 27.5 \mathrm{~kg} / \mathrm{m}^{2}$, and those with $\mathrm{BMI}>27.5 \mathrm{~kg} / \mathrm{m}^{2}$. Descriptive statistics included mean and standard deviation (SD) for continuous variables and proportion for categorical variables. Normal distribution of the data was tested using the Kolmogorov-Smirnov test. Means and frequency were compared using analysis of variance (ANOVA) test and chi-square test among the three groups, respectively. Correlation between the variables was analyzed using Pearson's correlation coefficient or Spearman's correlation coefficient according to data normality.

Multiple regression analysis was performed to identify the variables that significantly contributed to the level of knee pain (NRS) and health-related quality of life (EQ-5D), which were dependent variables. Candidate independent variables were selected and included in the regression model when the variable showed $p<0.1$ in the correlation tests. All statistical analyses were performed using SPSS version 20.0 (IBM Corp., Armonk, NY, USA), with statistical significance set at $p<0.05$.

\section{Results}

The characteristics of the patients included in the analysis are given in Table 1.

In all subjects, the severity of radiographic osteoarthritis (Kellgren-Lawrence grade) $(p<0.001)$ was the significant factor affecting the level of knee pain, whereas age $(p<0.001)$ and level of knee pain $(p<0.001)$ were the factors significantly affecting EQ-5D (Table 2). In the subgroup of women with BMI $\leq 22.5 \mathrm{~kg} / \mathrm{m}^{2}$, Kellgren-Lawrence grade $(p<0.001)$ was the significant factor affecting the level of knee pain, and age $(p<0.001)$ and level of knee pain $(p<0.001)$ significantly contributed to EQ-5D (Table 3$)$. In the subgroup of women with $22.5 \mathrm{~kg} / \mathrm{m}^{2}<\mathrm{BMI} \leq 27.5 \mathrm{~kg} / \mathrm{m}^{2}$, the Kellgren-Lawrence grade $(\mathrm{p}<0.001)$ and percentage 
change of weight during the past year $(p=0.006)$ were found to be significant factors affecting the level of knee pain. Age $(p=0.002)$, level of knee pain $(p<0.001)$, and weekly hours of walking $(p=0.018)$ were the factors that significantly affected EQ-5D in this subgroup (Table 4). In the subgroup of women with $B M l>27.5 \mathrm{~kg} / \mathrm{m}^{2}$, age $(p=0.031)$ was the significant factor affecting the level of knee pain, and level of knee pain $(p=0.002)$ and weekly hours of moderate-intensity activity $(p=0.010)$ were the factors that significantly contributed to EQ-5D (Table 5).

For the correlation between activity and weight change, weekly hours of walking was the only factor that was significantly correlated with percentage change of weight during the past year $(r=0.215, p=0.032)$ in the subgroup of women with BMI>27.5 kg/m². There was no significant correlation between activity and weight change in the other subgroups.

\section{Discussion}

This study investigated the factors affecting level of knee pain and health-related quality of life (EQ-5D), focusing on weight change and activity in community-based women aged 50 years and older with knee osteoarthritis. Important confounding factors were excluded from the data, such as presence of malignancy and osteoarthritis medication. We analyzed the data as subgroups stratified according to BMI. Weight change and activity showed different effects on level knee pain and health-related quality of life according to BMI subgroups.

In our whole cohort, BMI showed no significant correlation with knee pain or health-related quality of life. This is contrary to clinical consensus and previous study results that obesity has an important factor in the development and progression of osteoarthritis in terms of mechanical loading and biochemical pathway affecting inflammatory processes related with lipid metabolism[18, 26, 28, 34]. The authors considered that $\mathrm{BMI}$ is a critical factor in pain and health-related quality of life and stratified the whole cohort according to BMI, specifically designed for East Asian Women[35]; the most optimal BMI range (showing the lowest mortality), above and below the optimal range.

In our study, contrary to previous studies[28, 34], weight change during a year did not show significant correlation with the level of knee pain for the whole group of women aged 50 years and older with knee osteoarthritis (Kellgren-Lawrence grade $\geq 2$ ). The effect of weight change on knee pain showed differences according to BMI ranges. Weight change did not significantly affect the level of knee pain in women above and below the optimal range of BMI, but it showed significant effect on the level of knee pain in women within the optimal range of $\mathrm{BMI}\left(22.5 \mathrm{~kg} / \mathrm{m}^{2}<\mathrm{BMI} \leq 27.5 \mathrm{~kg} / \mathrm{m}^{2}\right)$. This result is not in concurrence with previous studies that showed that weight loss improved physical function and pain in overweight women with knee osteoarthritis[28, 34]. This difference might have been caused by the different characteristics of the study cohort or the effect of combined intervention such as exercise and diet. Therefore, weight loss alone might not decrease knee pain without appropriate exercise or concomitant intervention in obese patients with knee osteoarthritis. 
The amount of activity did not show any relationship with the level of knee pain in this community-based observational study, but it showed significant relationship with health-related quality of life. In the subgroup of women with $22.5 \mathrm{~kg} / \mathrm{m}^{2}<\mathrm{BMI} \leq 27.5 \mathrm{~kg} / \mathrm{m}^{2}$, weekly hours of walking showed significant positive correlation with EQ-5D. In the subgroup of women with BMl $27.5 \mathrm{~kg} / \mathrm{m}^{2}$, weekly hours of moderate-intensity activity showed significant negative correlation with EQ-5D. However, in both subgroups, the amount of activity did not show significant correlation with the weight changes. The amount of diet intake is considered to have an important role in weight changes[36-38].

There are some limitations to this study. First, this study was essentially a cross-sectional study depending on health-related questionnaire and specific examination. Therefore, causal relationship between the independent and dependent variables is not certain. Further longitudinal study with relevant hypothesis is required to verify the causality of the variables. Second, we excluded confounding factors such as presence of malignancy and osteoarthritis medication because these variables could significantly affect the level of knee pain. However, this exclusion might not reflect the usual clinical situation, although the study setting could evaluate the factors affecting knee pain more precisely in a community-based population without any medical intervention for knee osteoarthritis.

In conclusion, the amount of weight change and physical activity could affect the level of knee pain and health-related quality of life separately. Our study results suggested that weight reduction via walking exercise could reduce knee pain and improve health-related quality of life in the subgroup of East Asian women with optimal range of BMI with knee osteoarthritis. However, the specific type of physical activity could impede the patients' health-related quality of life although it might help reduce the patient's weight. Therefore, more sophisticated intervention is required regarding physical activity and weight loss according to BMI ranges in women with knee osteoarthritis. Future studies with strictly designed diet and physical activity are required to elucidate the relationships among weight loss, knee pain, and healthrelated quality of life.

\section{Conclusion}

The effect of weight change on knee pain could be different according to BMI ranges. Walking activity could improve the quality of life in women with optimal BMI range. Moderate intensity activity could impair the quality of life in obese women.

\section{Abbreviations}

BMI: Body mass index; EQ-5D: EuroQOL five-dimension; NRS: Numerical rating scale; ANOVA: Analysis of variance

\section{Declarations}

\section{Acknowledgements}


The authors wish to thank Jung Hee Yoon and Hana Park for their technical support.

\section{Funding}

This research was supported by the Bio \& Medical Technology Development Program of the National Research Foundation (NRF) funded by the Ministry of Science \& ICT(NRF- 2017M3A9D8064200).

\section{Availability of data and materials}

The data set supporting the conclusion of this article is available on request

to the corresponding author.

\section{Authors' contributions}

All authors on this manuscript (CBC, YC, SBK, CYC, MSP and $\mathrm{KML}$ ) made significant contributions to the study design. $\mathrm{CBC}$, SBK and CYC were involved in the conception and design of the study, acquisition of data. CBC, YC, MSP and KML were involved in the analysis and interpretation of data, as well as drafting the manuscript. All authors gave final approval of the version to be published.

\section{Consent for publication}

Not applicable

\section{Competing interests}

The authors declare that they have no competing interests.

\section{Author details}

1 Department of Orthopaedic Surgery, SMG-SNU Boramae Medical Center, Seoul National University College of Medicine, 20, Boramae-ro 5-gil, Dongjak-gu, Seoul 07061 South Korea. 2 Department of Orthopaedic Surgery, Kosin University Gospel Hospital, 262, Gamcheon-ro, Seo-gu, Busan 49267, South

Korea. 3 Department of Orthopaedic Surgery, Seoul National University Bundang Hospital, 82 Gumi-ro 173 Beon-gil, Bundang-Gu, Sungnam, Gyeonggi 13620, South Korea.

\section{References}


1. Bindawas SM, Vennu V, Auais M: Health-related quality of life in older adults with bilateral knee pain and back pain: data from the Osteoarthritis Initiative. Rheumatol Int 2015, 35(12):2095-2101.

2. Kiadaliri AA, Lamm CJ, de Verdier MG, Engstrom G, Turkiewicz A, Lohmander LS, Englund M: Association of knee pain and different definitions of knee osteoarthritis with health-related quality of life: a population-based cohort study in southern Sweden. Health Qual Life Outcomes 2016, 14(1):121.

3. Lowry V, Ouellet P, Vendittoli PA, Carlesso LC, Wideman TH, Desmeules F: Determinants of pain, disability, health-related quality of life and physical performance in patients with knee osteoarthritis awaiting total joint arthroplasty. Disabil Rehabil 2018, 40(23):2734-2744.

4. Rejeski WJ, Shumaker S: Knee osteoarthritis and health-related quality of life. Med Sci Sports Exerc 1994, 26(12):1441-1445.

5. Bartley EJ, King CD, Sibille KT, Cruz-Almeida Y, Riley JL, 3rd, Glover TL, Goodin BR, Sotolongo AS, Herbert MS, Bulls HW et al: Enhanced Pain Sensitivity Among Individuals With Symptomatic Knee Osteoarthritis: Potential Sex Differences in Central Sensitization. Arthritis Care Res (Hoboken) 2016, 68(4):472-480.

6. Dieppe PA, Lohmander LS: Pathogenesis and management of pain in osteoarthritis. Lancet 2005, 365(9463):965-973.

7. Finan PH, Buenaver LF, Bounds SC, Hussain S, Park RJ, Haque UJ, Campbell CM, Haythornthwaite JA, Edwards RR, Smith MT: Discordance between pain and radiographic severity in knee osteoarthritis: findings from quantitative sensory testing of central sensitization. Arthritis Rheum 2013, 65(2):363-372.

8. Holt RJ, Fort JG, Grahn AY, Kent JD, Bello AE: Onset and durability of pain relief in knee osteoarthritis: Pooled results from two placebo trials of naproxen/esomeprazole combination and celecoxib. Phys Sportsmed 2015, 43(3):200-212.

9. Jordan J, Luta G, Renner J, Dragomir A, Hochberg M, Fryer J: Knee pain and knee osteoarthritis severity in self-reported task specific disability: the Johnston County Osteoarthritis Project. J Rheumato/ 1997, 24(7):1344-1349.

10. Naugle KM, Riley JL, 3rd: Self-reported physical activity predicts pain inhibitory and facilitatory function. Med Sci Sports Exerc 2014, 46(3):622-629.

11. Aree-Ue S, Kongsombun U, Roopsawang I, Youngcharoen P: Path model of factors influencing healthrelated quality of life among older people with knee osteoarthritis. Nurs Health Sci 2019.

12. Bastick AN, Belo JN, Runhaar J, Bierma-Zeinstra SM: What Are the Prognostic Factors for Radiographic Progression of Knee Osteoarthritis? A Meta-analysis. Clin Orthop Relat Res 2015, 473(9):2969-2989. 
13. Creamer P, Lethbridge-Cejku M, Costa P, Tobin JD, Herbst JH, Hochberg MC: The relationship of anxiety and depression with self-reported knee pain in the community: data from the Baltimore Longitudinal Study of Aging. Arthritis Care Res 1999, 12(1):3-7.

14. Kim KW, Han JW, Cho HJ, Chang CB, Park JH, Lee JJ, Lee SB, Seong SC, Kim TK: Association between comorbid depression and osteoarthritis symptom severity in patients with knee osteoarthritis. $J$ Bone Joint Surg Am 2011, 93(6):556-563.

15. Nakamura J, Oinuma K, Ohtori S, Watanabe A, Shigemura T, Sasho T, Saito M, Suzuki M, Takahashi K, Kishida S: Distribution of hip pain in osteoarthritis patients secondary to developmental dysplasia of the hip. Mod Rheumatol 2013, 23(1):119-124.

16. Rahbar M, Shimia M, Toopchizadeh V, Abed M: Association between knee pain and low back pain. $J$ Pak Med Assoc 2015, 65(6):626-631.

17. Rainville J, Lopez E: Comparison of radicular symptoms caused by lumbar disc herniation and lumbar spinal stenosis in the elderly. Spine (Phila Pa 1976) 2013, 38(15):1282-1287.

18. Felson DT: Obesity and vocational and avocational overload of the joint as risk factors for osteoarthritis. J Rheumatol Supp/ 2004, 70:2-5.

19. Nteeba J, Ortinau LC, Perfield JW, 2nd, Keating AF: Diet-induced obesity alters immune cell infiltration and expression of inflammatory cytokine genes in mouse ovarian and peri-ovarian adipose depot tissues. Mol Reprod Dev 2013, 80(11):948-958.

20. Rakotoarivelo V, Lacraz G, Mayhue M, Brown C, Rottembourg D, Fradette J, llangumaran S, Menendez A, Langlois MF, Ramanathan S: Inflammatory Cytokine Profiles in Visceral and Subcutaneous Adipose Tissues of Obese Patients Undergoing Bariatric Surgery Reveal Lack of Correlation With Obesity or Diabetes. EBioMedicine 2018, 30:237-247.

21. Coggon D, Reading I, Croft P, McLaren M, Barrett D, Cooper C: Knee osteoarthritis and obesity. Int J Obes Relat Metab Disord 2001, 25(5):622-627.

22. Isla Pera P, Ferrer MC, Nunez Juarez M, Nunez Juarez E, Macia Soler L, Lopez Matheu C, Rigol Cuadra A, Perez MH, Marre D: Obesity, knee osteoarthritis, and polypathology: factors favoring weight loss in older people. Patient Prefer Adherence 2016, 10:957-965.

23. Lee R, Kean WF: Obesity and knee osteoarthritis. Inflammopharmacology 2012, 20(2):53-58.

24. Marks R: Obesity profiles with knee osteoarthritis: correlation with pain, disability, disease progression. Obesity (Silver Spring) 2007, 15(7):1867-1874.

25. Salih S, Sutton P: Obesity, knee osteoarthritis and knee arthroplasty: a review. BMC Sports Sci Med Rehabil 2013, 5(1):25. 
26. Zheng $\mathrm{H}$, Chen $\mathrm{C}$ : Body mass index and risk of knee osteoarthritis: systematic review and metaanalysis of prospective studies. BMJ Open 2015, 5(12):e007568.

27. Bindawas SM: Relationship between frequent knee pain, obesity, and gait speed in older adults: data from the Osteoarthritis Initiative. Clin Interv Aging 2016, 11:237-244.

28. McVinnie DS: Obesity and pain. Br J Pain 2013, 7(4):163-170.

29. Bedson J, Croft PR: The discordance between clinical and radiographic knee osteoarthritis: a systematic search and summary of the literature. BMC Musculoskelet Disord 2008, 9:116.

30. Spector TD, Hart DJ, Byrne J, Harris PA, Dacre JE, Doyle DV: Definition of osteoarthritis of the knee for epidemiological studies. Ann Rheum Dis 1993, 52(11):790-794.

31. Chun MY: Validity and reliability of korean version of international physical activity questionnaire short form in the elderly. Korean J Fam Med 2012, 33(3):144-151.

32. Bilbao A, Garcia-Perez L, Arenaza JC, Garcia I, Ariza-Cardiel G, Trujillo-Martin E, Forjaz MJ, MartinFernandez J: Psychometric properties of the EQ-5D-5L in patients with hip or knee osteoarthritis: reliability, validity and responsiveness. Qual Life Res 2018, 27(11):2897-2908.

33. Conner-Spady BL, Marshall DA, Bohm E, Dunbar MJ, Loucks L, Al Khudairy A, Noseworthy TW: Reliability and validity of the EQ-5D-5L compared to the EQ-5D-3L in patients with osteoarthritis referred for hip and knee replacement. Qual Life Res 2015, 24(7):1775-1784.

34. Goulston LM, Kiran A, Javaid MK, Soni A, White KM, Hart DJ, Spector TD, Arden NK: Does obesity predict knee pain over fourteen years in women, independently of radiographic changes? Arthritis Care Res (Hoboken) 2011, 63(10):1398-1406.

35. Zheng W, McLerran DF, Rolland B, Zhang X, Inoue M, Matsuo K, He J, Gupta PC, Ramadas K, Tsugane $\mathrm{S}$ et al: Association between body-mass index and risk of death in more than 1 million Asians. $N$ Engl $J$ Med 2011, 364(8):719-729.

36. Fuglestad PT, Jeffery RW, Sherwood NE: Lifestyle patterns associated with diet, physical activity, body mass index and amount of recent weight loss in a sample of successful weight losers. Int $J$ Behav Nutr Phys Act 2012, 9:79.

37. Raynor HA, Jeffery RW, Phelan S, Hill JO, Wing RR: Amount of food group variety consumed in the diet and long-term weight loss maintenance. Obes Res 2005, 13(5):883-890.

38. Whatley JE, Gillespie WJ, Honig J, Walsh MJ, Blackburn AL, Blackburn GL: Does the amount of endurance exercise in combination with weight training and a very-low-energy diet affect resting metabolic rate and body composition? Am J Clin Nutr 1994, 59(5):1088-1092. 


\section{Tables}

Due to technical limitations, table is only available as a download in the supplemental files section"

\section{Figures}

1956 patients were screened

- KNHANES (1998 to 2011)

- Women aged $\geq 50$ years

1126 were excluded

$\mathrm{KL}$ grade 1

830 patients were screened

- Women aged $\geq 50$ years

- $\mathrm{KL}$ grade $\geq 2$

612 patients were screened

- Women aged $\geq 50$ years

- $\mathrm{KL}$ grade $\geq 2$

- OA medication (-)

218 were excluded

OA medication (+)

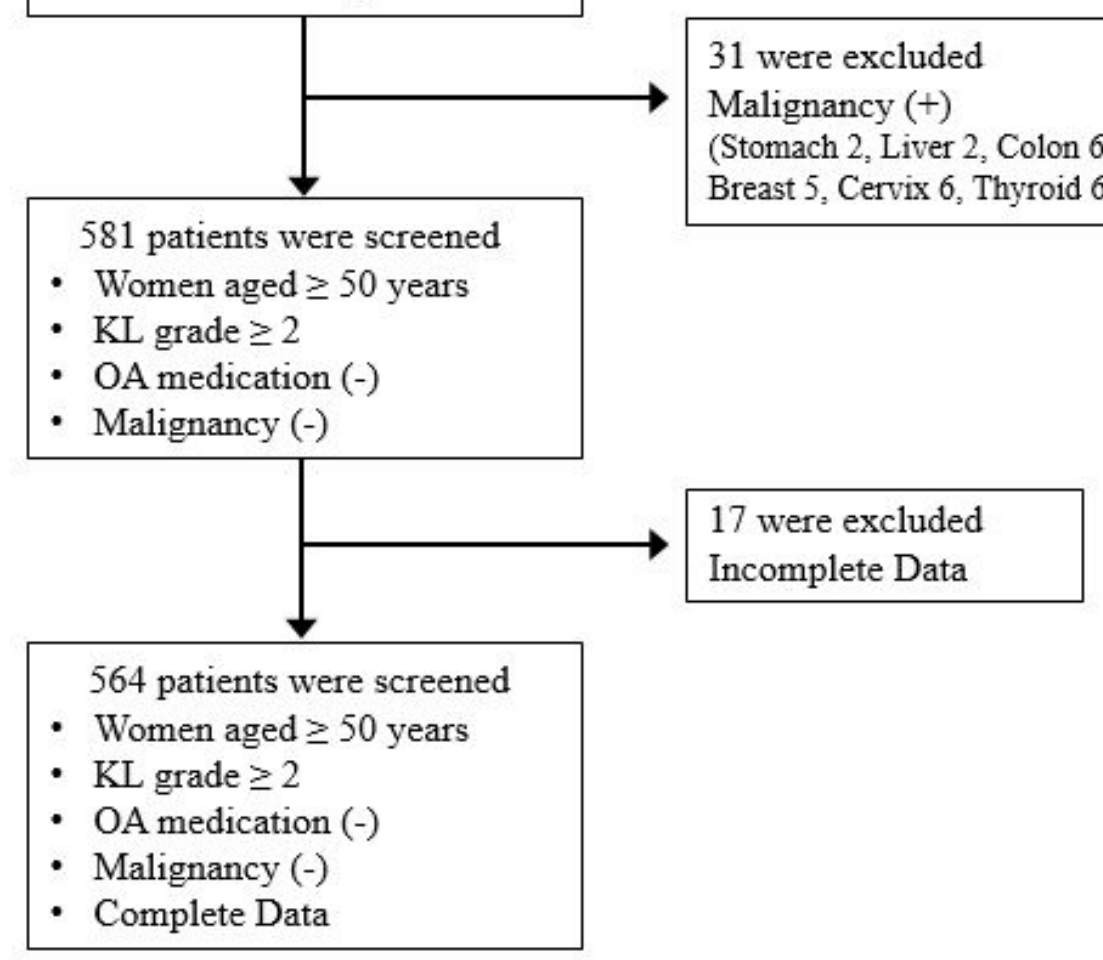

Figure 1 


\section{Supplementary Files}

This is a list of supplementary files associated with this preprint. Click to download.

- Table3.docx

- Table4.docx

- Table1.docx

- Table5.docx

- Table2.docx 